\title{
GENDRIFICANDO O MITO DE SUCESSÃO EM HESÍODO E NO ANTIGO ORIENTE PRÓXIMO
}

\author{
Adrian Kelly* \\ Tradução de Camila Aline Zanon**
}

Recebido em: 03/11/2019

Aprovado em: 21/11/2019

RESUMO: Este artigo reexamina um dos casos mais famosos de interação, o chamado Mito de Sucessão encontrado nas tradições grega arcaica, acadiana e hurro-hitita. Ele sugere que a versão dessa narrativa na Teogonia de Hesíodo, em lugar de indicar um modelo simplista de derivação direta, toca em um processo de interação mais rico e complexo, e que, portanto, esse nexo de textos do Oriente Próximo - incluindo a Canção de Emergência hitita (que costumava ser chamada Canção de Kumarbi), mas acrescentando a Teogonia de Dunnu e o Enuma Elish acadianos e uma variedade de narrativas posteriores da tradição greco-fenícia - pode indicar algo de fundamental sobre cada cultura, especificamente o modo pelo qual os gregos da época arcaica percebiam o gênero como um elemento essencial na sua construção dessas narrativas: ou seja, a figura da esposa-mãe, que nas tradições próximo-orientais pode assumir, e de fato assume, uma variedade de papéis, é consistentemente reduzida a uma função desestabilizadora, minando e subvertendo o domínio da divindade marido-pai. O estudo desses textos serve como uma ilustração clara do modo pelo qual a analogia transcultural é mais recompensadora do que uma genealogia buscada e definida de maneira estrita, que já foi a moda dominante do estudo comparativo no campo dos Estudos Clássicos.

PALAVRAS-CHAVE: Genealogia; sexo; gênero; Hesíodo; Oriente Próximo; Enuma Elish; Canção de Emergência; Teogonia de Dunni; Teogonia; Homero; Grécia arcaica; orientalizante.

GENDERING THE SUCCESSION MYTH IN HESIOD AND THE ANCIENT NEAR EAST
*University of Oxford adrian.kelly@balliol.ox.ac.uk **Pós-doutoranda, Departamento de Letras Clássicas e Vernáculas, Universidade de São

Paulo.

Bolsista FAPESP

camila.zanon@gmail.com 
ABSTRACT: This paper re-examines one of the most famous of all cases of interaction, the so-called Succession Myth found in the early Greek, Akkadian, and Hurro-Hittite traditions. It suggests that, rather than indicating a simplistic model of direct derivation, Hesiod's version of this story in his Theogony hints at a much richer and more complex process of interaction, and that therefore this nexus of Near Eastern texts - including the Hittite Song of Emergence (which used to be called the Song of Kumarbi), but adding the Akkadian Theogony of Dunnu and Enuma Elish, and a variety of later stories from the Phoenico-Greek tradition - can indicate something fundamental about each culture, but specifically the way in which the early Greeks viewed gender as an essential element in their construction of these stories: that is, the wife-mother figure, who in NE traditions can and does play a variety of roles, is consistently reduced to a destabilising function, undermining and subverting the rule of the husband-father deity. The study of these texts serves as a clear illustration of the way in which cross-cultural analogy is more rewarding than narrowly pursued and defined genealogy, which was once the dominant mode of comparative study in Classical quarters.

KEYWORDS: Genealogy; sex; gender; Hesiod; Near East; Enuma Elish; Song of Emergence; Theogony of Dunnu; Theogony; Homer; early Greece; Orientalising.

\section{INTRODUÇÃO}

$\mathrm{E}$ ste artigo tem início com dois pedidos de desculpa: o primeiro aos pesquisadores de literatura do Oriente Próximo por seus textos serem usados mais uma vez basicamente para elucidar algo acerca de um dos mais antigos autores gregos; e o segundo ao leitor por ter de se voltar novamente a um assunto bem-conhecido - a relação entre o assim chamado "Mito de Sucessão" de Hesíodo e seus vários comparanda nas tradições do Antigo Oriente Próximo. ${ }^{2}$ Talvez ambos os pedidos de desculpa possam ser justificados. Alhures argumentei que há espaço para um considerável ceticismo em relação ao entusiasmo com o qual os classicistas se filiam a uma versão, um tanto simplista, do ex Oriente lux. ${ }^{3}$ Essa conclusão não é decorrente de um desejo de evitar que as literaturas do

\footnotetext{
${ }^{1}$ Gostaria de agradecer à minha antiga aluna, Laura Wills, com cujas perspectivas aprendi muito quando explorei essa área pela primeira vez enquanto supervisionava seu trabalho de conclusão de curso sobre deusas gregas e próximo-orientais. Também gostaria de agradecer a vários colegas especificamente Bernardo Ballesteros Petrella, Johannes Haubold, Ian Rutherford, Selena Wisnom, e especialmente Christopher Metcalf - por me ajudarem a tentar superar o fato de que, na verdade, sou meramente um pesquisador de literatura grega antiga. Por fim, agradeço deveras a Antonio Orlando Dourado-Lopes e Teodoro Rennó Assunção e ao público do II Colóquio Internacional sobre Poesia Grega Arcaica do NEAM / UFMG: Poesia Hexamétrica, Universidade Federal de Minas Gerais, Brasil, pelo convite, hospitalidade e atenção a este artigo e a seu conteúdo. Uma versão mais longa deste artigo será publicada em Kelly, 2020, no prelo. N. T.: Outras versões do mito que lhe são comparáveis.

${ }^{2} \mathrm{O}$ termo é mantido aqui, apesar das críticas justas de van Dongen (2014); seu uso aqui não implica qualquer tipo de uniformidade cultural, mas continua a ser uma abreviação conveniente.

${ }^{3}$ Cf. Kelly (2008; 2014). N. T.: "do Oriente [vem] a luz".
} 
Oriente Próximo "reivindiquem o leitor de Homero" ou de rejeitar uma "leitura engajada" dessas literaturas ${ }^{4}$ - de fato, este artigo tenta oferecer tal leitura do Mito de Sucessão num certo número de culturas antigas. De modo diverso, minhas objeções são metodológicas: embora cada vez mais marginal, a abordagem ainda dominante desse material por parte dos Estudos Clássicos permanece nas mãos de uma "paralelomania" que supervaloriza semelhanças e diminui o valor das diferenças entre essas tradições e tenta transformar os próprios Homero e Hesíodo em transmissores, se não em verdadeiros tradutores, do material próximo-oriental.

Talvez não seja surpreendente que isso tenha acontecido, quando nos lembramos de que os parâmetros intelectuais dos Estudos Clássicos, simplesmente como os de qualquer outra disciplina, são formados por sua herança. Duas correntes em particular têm tido papéis importantes aqui: primeiro, a relação mais tardia entre a literatura grega e a romana; e segundo, a autoridade da "crítica textual" - o processo pelo qual a versão autêntica e original de um texto é estabelecida ao se encontrar e ponderar suas fontes manuscritas acessíveis e individuais. Era quase inevitável que as certezas que predicam essas relações e processos fossem transpostas de volta para o estudo dos primórdios da literatura grega, com níveis variáveis de autoconsciência. ${ }^{5}$ Entretanto, além de recender fortemente a concepção Whig da história, esse tipo de personalização ou especificação simplifica demais os meios, a complexidade e a extensão dos contatos culturais entre a Grécia e seus vizinhos, que deve recuar até mesmo à Idade do Bronze Médio. Em síntese, deveríamos preferir uma "longue durée"" à abordagem "big bang" de alguns dos meus colegas. ${ }^{7}$

\section{Tradições EM Diálogo}

Considerando-se tais predileções metodológicas, classicistas têm sido há muito tempo atraídos pelo Mito de Sucessão na Teogonia de Hesíodo, e a pesquisa moderna mantém quase em uníssono que suas semelhanças com um texto hurro-hitita do século XIII a.C., conhecido como Canção de Emergência (CTH 344), são tão precisas e abrangentes que só podem ser explicadas em termos de empréstimos que os gregos teriam feito da narrativa da tradição hurro-hitita. ${ }^{8}$ Decerto, há muito a questão mais premente tem sido não se, mas quando e onde

\footnotetext{
${ }^{4}$ Haubold (2013, p. 32).

${ }^{5}$ Cf. Currie (2016), que usa declaradamente os poetas augustanos e suas dinâmicas como um modelo para os primórdios da história da literatura grega.

${ }^{6} \mathrm{~N}$. T.: longa duração.

${ }^{7}$ Por exemplo, cf. Bachvarova (2016), com crítica em Metcalf (2017).

${ }^{8}$ Para discussões recentes com (volumosa) bibliografia mais antiga, cf. West (1997, p. 103-5, p. $278-$ 92); Rutherford (2009, p. 9-36); López-Ruiz (2010, p. 87-94); Rutherford (2018, especialmente p. 4-6, p. 12-13). O título foi recuperado apenas recentemente (Corti, 2007; van Dongen, 2011, p. 182, n. 3 , intitula-o Song of Going Forth [Canção do Surgimento]), e o texto é geralmente associado a outras tabuinhas para formar o que se conhece como Ciclo do Reinado no Céu (também conhecido como Ciclo de Kumarbi), embora até mesmo o termo "ciclo" atualmente não esteja fora de controvérsia (Archi, 2009, p. 211).
} 
esse "evento" ocorreu. Além disso, deveríamos optar por uma abordagem personalista, na qual o próprio Hesíodo praticou o empréstimo, ou por uma mais centrada na tradição, em que essas características teriam sido parte do épos grego ao longo de muitas gerações antes do próprio Hesíodo? ${ }^{9}$ Vozes céticas têm se pronunciado, ${ }^{10}$ mas parece haver de fato um bom caso prima facie $e^{11}$ para propor algum tipo de interação direta entre tradições aqui.

Antes de examinar as semelhanças que deram origem a essa conclusão, devemos dar um passo para trás, metodológica e diacronicamente. Quando são levantados argumentos sobre os gregos "tomando emprestado" ou "herdando" elementos das culturas do Oriente Próximo, geralmente há pouca ou nenhuma consideração do que existia antes do suposto momento da derivação. Quando pesquisadores evocam o pano de fundo indo-europeu nessa conexão, geralmente estão tentando negar ou qualificar essa derivação, e assim usam esse pano de fundo de um modo excludente: se um elemento aparentemente "próximo-oriental" num texto grego pode encontrar paralelo num ambiente indo-europeu, então tal elemento não é mais evidência para influência do Oriente Próximo. Esse é um argumento importante a se evocar contra aqueles pesquisadores que são rápidos em sugerir derivação, especialmente quando procuram isolar um momento ou pessoa responsável em particular, mas a força do argumento deve depender de cada exemplo, e propostas excluídas de antemão não poderão estabelecer a utilidade ou o interesse a ser encontrado no pano de fundo indo-europeu.

Esse é especialmente o caso do Mito de Sucessão, que vários pesquisadores têm estudado numa série de contextos indo-europeus. Paralelos do "reinado no céu" têm sido encontrados em vários níveis de especificidade nas mitologias iraniana, indiana e nórdica: Stig Wikander percebeu um paralelo próximo com o Shähnämeh ou "Épico dos Reis" iraniano do final do século X d.C. (embora descarte muito rapidamente o efeito da tradição mesopotâmica mais antiga); Dominique Briquel contrastou o ódio e a violência na tradição grega com a relativa pacificidade no modo com que padrões e motivos não muito paralelos são trabalhados no Mahäbhärata; e C. Scott Littleton traçou o "mesmo quadro amplo" para as narrativas nórdicas de criação. ${ }^{12}$ Mais recentemente, Nick Allen comparou o quadro em Hesíodo com as cinco gerações de heróis-deuses no Mahābhärata para reconstruir uma "protonarrativa" indo-europeia, com vários pontos de contato, embora mais difusos. ${ }^{13}$ Entretanto, mesmo deixando de lado a questão das posições temporal e histórica relativas, nenhuma dessas

\footnotetext{
${ }^{9}$ Conquanto excelente em tudo mais, o estudo de van Dongen (2011, p. 190 e 194s.) tenta esquematizar o próprio papel de Hesíodo no processo, embora não negue a circulação da narrativa em contextos gregos à época, e prossegue largamente na base um tanto subjetiva do "quão engenhosamente o esquema tripartite do tema funciona na Teogonia" (p. 190). Strauss Clay e Gilan (2014) sugerem uma conexão direta baseada numa pequena e precisa incongruência verbal tanto em Hesíodo como na Canção de Emergência. Para uma série semelhante de argumentos tradicionais versus personalistas sobre a relação de Homero com textos e tradições do Oriente Próximo, cf. Kelly (2008).

${ }^{10}$ Cf. esp. Mondi (1990).

${ }^{11} \mathrm{~N}$. T.: à primeira vista.

${ }^{12}$ Wikander (1952); Briquel (1980); Littleton (1970a, sem. 1970b).

${ }^{13}$ Allen (2004); cf. também Sergent (1997, p. 333-5).
} 
tradições mostra a semelhança sistêmica à narrativa grega que vemos na Canção de Emergência, e alguns detalhes são, na melhor das hipóteses, paralelos bastante parciais.

Contudo, não devemos, como consequência, simplesmente descartar a importância desse material, já que

[1]es Hellènes, en même temps qu'ils ont assimilé des apports orientaux, ont pu les interpréter en fonction de conceptions indoeuropéennes. Finalement ce qui importe, c'est non la provenance ultime de tel élément du mythe -nom de Zeus ou idée de la lutte entre des générations divines - mais la manière dont ces traits s'ordonnent dans la représentation des Grecs en un système cohérent: ... à ce niveau la persistance de schémas indo-européens [se fait parfois] sentir, intégrant le cas échéant des données méditerranéennes ou orientales. ${ }^{14}$

Isto é, o pano de fundo indo-europeu provavelmente forneceu aos gregos uma série de narrativas, grosseiramente comparáveis entre si, sobre a transferência de poder entre gerações em contextos reais e divinos que abriram o caminho, por assim dizer, para processos de interação posterior, como E. J. Michael Witzel sugeriu. ${ }^{15}$ Pode-se colocar em dúvida se havia uma tradição indo-europeia consistente que continha todos ou a maioria dos elementos conhecidos em Hesíodo e na Canção de Emergência, ${ }^{16}$ ou seja, o conflito entre três gerações de deuses, a mutilação da primeira geração, a redefinição dos deuses vitoriosos e uma batalha final entre um novo regime e os deuses mais antigos. Mas podemos ter certeza de que, sem ao menos algumas dessas semelhanças, por mais distantes que elas pareçam, a interação entre a cultura grega e a hurro-hitita poderia bem ter sido "bloqueada". ${ }^{17}$

\footnotetext{
${ }^{14}$ N. T.: “[o]s helenos, ao mesmo tempo em que assimilaram as contribuições orientais, puderam interpretá-las em função de concepções indo-europeias. Por fim, o que importa não é a proveniência final de tal elemento do mito - o nome de Zeus ou a ideia da luta entre gerações divinas -, mas a maneira com que esses traços se ordenam na representação dos gregos em um sistema coerente: [...] nesse nível a persistência de esquemas indo-europeus [se faz por vezes] sentir, eventualmente integrando os dados mediterrâneos ou orientais". Briquel (1980, p. 247); cf. também Katz (2018, p. 63): "um óbvio desiderato para o estudo moderno de Hesíodo é, portanto, uma compreensão holística de como a pré-história indo-europeia e os análogos próximo-orientais contribuem juntos para a formação da linguagem e do pensamento hesiódicos”.

${ }^{15}$ Witzel (2011, p. 65-75, especialmente elemento 7 na tabela 2.7, e p. 161 para sistemas "Laurasianos" e sua interação).

${ }^{16}$ Cf. Littleton (1970a, p. 396-400). Ainda que estabelecêssemos que o "reinado no céu" era um padrão indo-europeu, ou ao menos uma possibilidade dentro dessa tradição, isso não mudaria concretamente o argumento deste artigo, pois as semelhanças do mito grego com a tradição hurro-hitita são muito mais próximas e mais numerosas do que com qualquer outra forma conhecida dessa narrativa. Para o cuidado necessário em relação a esses assuntos, cf. os sensatos comentários de Puhvel (1987, p. 22-3). ${ }^{17}$ Em relação a esse importante critério, cf. Rutherford (2020) quanto à análise de por que a narrativa sobre o combate de Baal com o Mar não adentra o mundo grego.
} 
É certo que a tradição grega não teve esse destino. Os paralelos entre a Teogonia do século VIII ou VII a.C. e a Canção de Emergência do século XIII a.C. são bem conhecidos, mas podem ser brevemente rememorados. Elas iniciam com a sequência Urano-CronoZeus do lado grego correspondendo de perto a Anu-Kumarbi-Teshshub/Tarhunta do lado hurro-hitita, mostrando a transferência de poder tripartite a partir do deus-céu para o deus astucioso e então para o deus-tempestade. Os detalhes compartilhados são também muito semelhantes: (i) Kumarbi arranca os genitais de Anu com os dentes como Crono ceifa os genitais de Urano com uma foice; e (ii) ambos, Kumarbi e Crono, engolem uma pedra - que depois se torna um objeto de culto - em lugar de uma criança; (iii) os deuses da terceira geração emergem do corpo do deus deposto (Crono vomita, Kumarbi dá à luz); e por fim (iv) Kumarbi, dando à luz Teshshub, parece também encontrar algum tipo de paralelo em Zeus engolindo Métis e no posterior nascimento de Atena na Teogonia (886-900; 924-9). ${ }^{18}$

Ainda assim, a tradição hurro-hitita não é a única a apresentar algum tipo de paralelo com o Mito de Sucessão da Teogonia. O épico da criação babilônico do final do segundo milênio a.C., Enuma Elish, compartilha (i) a ideia de que o desgosto do pai por seus filhos é a causa da atribulação (Urano \& Crono/Apsu), e (ii) o papel um tanto desestabilizador da deusa primordial feminina (Gaia/Tiamat) - um importante princípio no mito grego, como veremos, mas não do mesmo modo na tradição hurro-hitita (cf. adiante). Outra obra babilônica, a Teogonia de Dunnu - cujo texto é datado do primeiro milênio a.C., mas cuja narrativa é tão antiga quanto o início do segundo milênio - compartilha com Hesíodo um foco no incesto e na violência entre gerações, embora os detalhes sejam escassos. ${ }^{19}$

Conquanto seja claro que algumas das narrativas de Hesíodo sejam mais próximas da Canção de Emergência do que de outros textos listados aqui, a evidência não nos permite alcançar uma conclusão firme sobre as questões de quando e onde qualquer interação tenha ocorrido: alguns pesquisadores defendem um cruzamento recuado por meio de uma interface anatólia durante a Idade do Bronze Tardio, enquanto outros sugerem uma rota mais direta, mais próxima temporalmente de Hesíodo na Idade do Ferro Inicial, através dos reinos neo-hititas no norte da Síria e/ou dos fenícios no Levante. ${ }^{20}$ Esse não é o foco deste artigo, embora muito da nossa evidência para o Mito de Sucessão no caso fenício venha por meio da obra de Fílon de Biblos, um grego do século I/II d.C., que afirma ter tido acesso a uma antiga cosmogonia fenícia de "Sanchuniathon". Preservada por Eusébio, o bispo de Cesareia no século IV d.C. (Preparação para o Evangelho 1.10.1-53), essa narrativa parece ressoar de vários modos a de Hesíodo e contém vários dos mesmos detalhes, tais como a castração de Urano - que é hostil a seus filhos - por parte de seu filho El/Crono. ${ }^{21}$ Quando lida em

${ }^{18}$ Para outros paralelos, especialmente aqueles envolvendo Tífon e a dispersão do sêmen que dá origem a Afrodite, cf. as obras listadas acima na nota 8.

${ }^{19}$ Para excelentes resumos de todo esse material, cf. as obras listadas acima na nota 8; para traduções inglesas, Lambert (2013) e López-Ruiz (2014a).

${ }^{20}$ Para um panorama recente e excelente das opções, cf. Rutherford (2018, p. 17-19), que sensatamente recusa reduzi-las dessa maneira.

${ }^{21}$ Cf. Littleton (1970a, p. 385), Cors i Meya (1999-2000), López-Ruiz (2010, p. 94-101). 
conjunto com os textos ugaríticos da Idade do Bronze Tardio, como o Ciclo de Baal do século XIV ou XIII a.C., essa narrativa pode fornecer outra pista das tradições nas quais Hesíodo ou seus ancestrais poderiam ter bebido, mas Erik van Dongen está correto em questionar seu valor comprobatório independente: Fílon escreve com um bom conhecimento de Hesíodo, e assim seu valor como evidência é um pouco questionável. ${ }^{22}$ Em todo caso, nem Fílon nem o antigo material ugarítico apresentam a característica crucial do Mito de Sucessão que nos concerne neste artigo, e assim não tomará mais parte nesta discussão.

Minha visão desse processo de interação é que ele foi um processo, provavelmente com vários pontos de contato, começando na Idade do Bronze Tardio, mas continuando até a Idade do Ferro Inicial, por meio de vários transmissores. Mas é isso mesmo? Isso é tudo que conseguimos dizer? Com base na evidência atual não conseguimos ser mais precisos? Pode parecer correto e cauteloso em termos genealógicos, mas certamente não é o único modo pelo qual classicistas podem buscar iluminação no Oriente Próximo, particularmente com esse empolgante nexo entre textos. Num artigo anterior que ninguém leu e com o qual ainda menos pessoas concordam, sugeri que as qualidades que distinguem a narrativa de batalha homérica, quando observadas lado a lado com as representações literárias de combate do Oriente Próximo, mostram exatamente quão diferente da de seus vizinhos - na verdade, quão bizarra - era a tradição épica grega em sua "estetização" e "narrativização" da batalha;, ${ }^{23}$ tais termos significam simplesmente que a batalha se torna o contexto e o tópico para uma narrativa interessante, em lugar de uma costumeira confirmação não episódica do poder sobrepujante do vencedor, ou de apoio divino por trás dele, como encontramos geralmente nas fontes próximo-orientais e egípcias. A questão da genealogia - embora tenda a apontar na direção do indo-europeu - parecia menos interessante do que a analogia, considerando o que a comparação com outras tradições pode nos revelar. Nesse caso, ela revelou que os gregos gostavam de descrições de batalhas longas, detalhadas e sinuosas, e quanto a isso estavam um tanto sozinhos entre as civilizações da Idade do Bronze Tardio na bacia do Egeu e na Mesopotâmia.

Como pesquisadores estão reconhecendo cada vez mais, temos que superar a catalogação de semelhanças e construção de genealogias e começar a pensar sobre o que o material próximo-oriental nos diz em termos analógicos - isto é, o que cada cultura ou

\footnotetext{
${ }^{22}$ Van Dongen (2011, especialmente p. 183-4).

${ }^{23}$ Kelly (2014). Para uma perspectiva diferente, que junta detalhes e motivos incidentais da maneira usual, cf. Rollinger (2020); para uma crítica de seu método, cf. Kelly (2008). Rollinger (2015) acusa este último artigo de falhar em reconhecer que o processo de adaptação muda o material. É difícil reconhecer de onde ele obteve essa impressão, e é confuso também, já que muitos dos pesquisadores criticados lá - mas elogiados por Rollinger - se baseiam precisamente na ideia de que as falhas de Homero em adaptar o material próximo-oriental são os casos mais evidentes de derivação, pois revelam traços da "fonte". Devemos tentar distinguir as semelhanças que são fortuitas ou resultado de desenvolvimentos nativos daquelas que são de fato paralelas, derivadas de fontes externas. De outro modo, não temos um método de pesquisa à nossa disposição - apenas um exercício catalográfico mascarado de método.
} 
texto está fazendo com elementos compartilhados ou comuns. Quando nos voltamos com esse espírito para o material comparativo do Mito de Sucessão, notamos imediatamente uma grande diferença entre a tradição próximo-oriental e a grega inicial (e no interior de ambas), isto é, o padrão como o encontramos narrado em Hesíodo (mas assumido em Homero e trabalhado de modos diferentes nos Hinos homéricos). Essa diferença, em suma, diz respeito ao gênero, ou ao papel desempenhado pelo gênero dentro da lógica do mito. ${ }^{24}$

Vamos olhar primeiro para o lado grego, tanto no interior quanto para além de Hesíodo: aqui é sempre a consorte principal agindo por meio dos filhos que debilita o pai, numa variedade de formas. ${ }^{25} \mathrm{Na}$ Teogonia, Gaia fica agastada com o tratamento do marido em relação a ela e aos filhos. Primeiro, ela procura voluntários dentre seus filhos para depor Urano e então arma Crono com uma foice de adamanto e "o instrui em relação ao completo

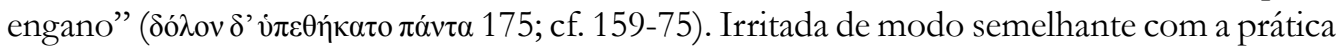
de Crono de engolir seus filhos assim que nascem, Reia consulta Gaia e Urano sobre os meios de evitar que a mesma coisa aconteça com Zeus. Por conselho deles, ela vai a Licto (onde é recebida por Gaia) para dar Zeus à luz, e então, em seu lugar, entrega a Crono uma pedra (459-91). Hera, a consorte derradeira, é mostrada em Hesíodo e alhures como tentando constantemente superar ou frustrar os desejos de Zeus ou de seus filhos, mas tendo muito pouca sorte no processo (Teog. 314-15, 328-9, 927-9). Com efeito, no padrão do Mito de Sucessão, ela é a "conspiradora materna” frustrada.

\begin{tabular}{|c|c|c|c|c|}
\hline & $\begin{array}{l}\text { Teogonia de } \\
\text { Hesíodo }\end{array}$ & $\begin{array}{c}\text { Canção de } \\
\text { Emergência }\end{array}$ & Enūma Elish & Teogonia de Dunnu \\
\hline A. & & Alalu & & $\mathrm{Ha}^{\supset}$ in \\
\hline união & - & & & Terra (filho?) \\
\hline filhos & - & - & & $?$ \\
\hline $\begin{array}{l}\text { conspiração } \\
\text { materna }\end{array}$ & & & & Terra com Shakkan \\
\hline deposição & & Alalu por Anu & & $\mathrm{Ha}_{\mathrm{in}} \supset_{\text {in }}$ [morto] por Shakkan \\
\hline 1. & Urano & Anu & Apsu & Shakkan (filho) \\
\hline união & Gaia (mãe) & & Tiamat & Terra (mãe) / Mar (filho) \\
\hline filhos & Urano evita & & $\begin{array}{l}\text { Apsu odeia, } \\
\text { Tiamat irritada }\end{array}$ & ? \\
\hline
\end{tabular}

${ }^{24}$ Diferencio "sexo", como uma função biológica, de "gênero", como um construto social, à maneira padrão. Para discussões recentes dessas questões no contexto do Oriente Próximo, cf., por exemplo, Parpola e Whiting (2002), Asher-Greve (2001), Bolger (2008), Asher-Greve e Westenholz (2013, p. 15-28), Budin (2014), Peled (2016), Cooper (2017); também adiante, nota 30.

${ }^{25}$ Cf. a obra fundadora de Bonnafé (1985, especialmente o cap. 5); mais recentemente, Lye (2018). 


\begin{tabular}{|c|c|c|c|c|}
\hline $\begin{array}{l}\text { conspiração } \\
\text { materna }\end{array}$ & Gaia e seus filhos & & Tiamat recusa & ? \\
\hline deposição & $\begin{array}{l}\text { Urano [castrado] } \\
\text { por Crono }\end{array}$ & $\begin{array}{l}\text { Anu [castrado] } \\
\text { por Kumarbi }\end{array}$ & \begin{tabular}{|l|} 
Apsu [morto] \\
por Ea (bisneto)
\end{tabular} & $\begin{array}{l}\text { Shakkan [morto] por Lahar, Terra } \\
\text { por Mar }\end{array}$ \\
\hline 2. & Crono (filho) & Kumarbi & \begin{tabular}{|l|} 
(Anshar) Ea | \\
Tiamat/Qingu
\end{tabular} & Lahar (filho) \\
\hline união & Reia (filho) & - & Damkina (mãe) & Mar (mãe) \\
\hline filhos & Crono devora & Kumarbi gera & $\begin{array}{l}\text { Tiamat et al. } \\
\text { odeiam }\end{array}$ & $?$ \\
\hline $\begin{array}{l}\text { conspiração } \\
\text { materna }\end{array}$ & $\begin{array}{l}\text { Reia com Gaia / } \\
\text { Urano }\end{array}$ & - & $\begin{array}{l}\text { Tiamat com } \\
\text { filhos, deuses } \\
\text { antigos }\end{array}$ & $?$ \\
\hline deposição & Crono por Zeus & $\begin{array}{l}\text { Kumarbi por } \\
\text { Teshshub }\end{array}$ & $\begin{array}{l}\text { Tiamat [morto] } \\
\text { por Marduk }\end{array}$ & Lahar \& Mar [mortos] por $[\mathrm{x}]$ \\
\hline 3. & Zeus (filho) & $\begin{array}{l}\text { Teshshub } \\
\text { (filho) }\end{array}$ & Marduk (filho) & [x] (filho) \\
\hline união & Hera (filho) etc. & - & - & Rio (s.) \\
\hline filhos & Zeus honra & - & $\begin{array}{l}\text { Marduk } \\
\text { engendra }\end{array}$ & ? \\
\hline $\begin{array}{l}\text { conspiração } \\
\text { materna }\end{array}$ & Gaia / Hera & - & - & ? \\
\hline deposição & Zeus mata Tífon & $\begin{array}{l}\text { Teshshub derrota } \\
\text { LAMMA, Prata, } \\
\text { Hedammu, } \\
\text { Ullikummi }\end{array}$ & - & [x] \& Rio mortos por [y] (abaixo) \\
\hline 4. & & & & [z](filho) \\
\hline união & & & & $\mathrm{Ga} \supset_{\mathrm{u}}$ (filho) \\
\hline filhos & & & & $?$ \\
\hline $\begin{array}{l}\text { conspiração } \\
\text { materna }\end{array}$ & & & & $?$ \\
\hline deposição & & & & {$[\mathrm{y}] \& \mathrm{Ga} \supset \mathrm{u}$ mortos por $[\mathrm{z}]$} \\
\hline
\end{tabular}

Curiosamente, Gaia e Urano estão constantemente envolvidos nos estágios subsequentes do Mito de Sucessão, envolvimentos que com frequência têm parecido aos pesquisadores como contraditórios: por um lado, eles aconselham Crono sobre o que poderia lhe acontecer nas mãos de seu filho (463-5) e, por outro, aconselham Reia sobre como fazer isso acontecer (474-6); eles avisam Zeus sobre o que poderia lhe acontecer nas mãos de seu filho (888-900), e é dito que Gaia, em várias outras ocasiões, garantiu ou auxiliou a sucessão 


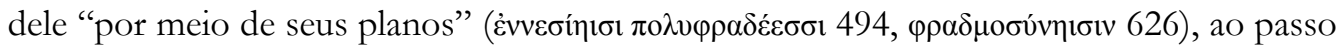
que ela produz Tífon aparentemente como o desafio final ao reinado de Zeus (820-2). Gaia é claramente a figura dominante nesse quadro de alianças alternantes, e sua ambiguidade deve ser explicada de modo semelhante pelo foco no gênero em Hesíodo ou na tradição grega de modo mais geral, uma função da ambivalência que emoldura a participação e o poder femininos.

A frustração de Hera é importante, pois a repetição do Mito de Sucessão é evitada na ambientação grega muito em razão das políticas sexuais de Zeus, tornadas manifestas de muitos modos ao longo do épos arcaico. Primeiro, Zeus engole Métis enquanto grávida e assim ele próprio gera Atena (Teog. 888-900), cujo nascimento representa a neutralização da ameaça a seu reinado: ela revela, por meio de sua eterna virgindade, que não desestabilizará Zeus produzindo um rival para desafiá-lo. Imediatamente após o nascimento de Atena na Teogonia (924-6), Hera gera Hefesto em razão da cólera contra o marido e, portanto, sem sua ajuda, e a conexão entre a partenogênese de Zeus - e a tentativa menos bem-sucedida de Hera de emulá-la - é tornada ainda mais evidente no Hino homérico a Apolo (307-30ss.).

Em segundo lugar, esse comportamento é entrelaçado a outro aspecto das políticas sexuais olímpicas, aquele que diz respeito a Zeus ter prole poderosa com várias deusas que não são sua consorte oficial - Apolo de Leto, Hermes de Maia, Dioniso de Sêmele, Héracles de Alcmena etc. (Teog. 918-20, 938-9, 940-2, 943-4 etc.). Essas figuras o ajudarão a estabelecer seu reinado ao livrar a terra de monstros e criaturas primordiais cujas ações subversivas são frequentemente engendradas ou encorajadas pelas divindades femininas do Mito de Sucessão. Tifeu, por exemplo, é o filho de Gaia em Hesíodo (e de Hera no Hino homérico a Apolo 307-9), enquanto Hera nutre a Hidra de Lerna (314-5) e o Leão de Nemeia (328-9). Esses "desafiadores de monstros" certamente têm uma longa e variada tradição anatólia, mesopotâmica e ugarítica -, mas essa não é minha preocupação aqui. ${ }^{26}$ Todavia, não é incidental nem uma metáfora vazia que a geração de Tifeu em Hesíodo seja realizada

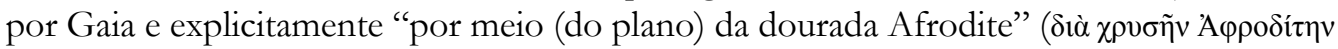
Teog. 822). Gênero, gênero, em toda parte. ${ }^{27}$

Em terceiro lugar, como o outro lado dessa moeda, o autocontrole genealógico de Zeus é estendido a seu controle sobre a liberdade sexual de outros, algo evidente pela própria estrutura da Teogonia, que se encerra com uniões de significância cosmológica decrescente, terminando por fim com os filhos das deusas e seus amantes. ${ }^{28}$ Mas isso é também um conceito fundamental ao longo do épos arcaico grego, com, por exemplo, Calipso se queixando dos diferentes pesos e medidas dos deuses em relação aos assuntos de liberdade sexual (Od.

\footnotetext{
${ }^{26}$ Para reavaliações recentes desse tema na cultura próximo-oriental antiga, cf. os ensaios em Scurlock e Beal (2013); acerca da tradição indo-europeia, cf. Watkins (1995), West (2007, p. 255-9); para a perspectiva mais ampla possível, cf. Witzel (2011, p. 148-54).

${ }^{27}$ Para uma perspectiva diferente, cf. Metcalf (2015, p. 183, n. 36).

${ }^{28}$ Cf. Kelly (2007, p. 389-94). Se esses catálogos ao fim da obra são ou não autenticamente de Hesíodo não está resolvido, mas isto é irrelevante para o meu argumento: eles eram desde muito cedo parte da tradição desse poema.
} 
5, 116-29), o plano de Zeus de casar sua filha Perséfone no Hino homérico a Deméter, e Afrodite tendo seus poderes cerceados e voltados contra ela por Zeus no Hino homérico a Afrodite.

Em outras palavras, a gendrificação do Mito de Sucessão em Hesíodo repercute um processo de gendrificação que é fundamental, de várias maneiras diferentes, para a totalidade do Götterapparat ${ }^{29}$ no épos arcaico grego. Mas quando nos voltamos para o material próximooriental, não vemos esse tipo de gendrificação em nenhuma versão do Mito de Sucessão. ${ }^{30}$ Isso não significa dizer que as políticas sexuais são desimportantes nessas tradições, como veremos, mas que os gregos parecem entrelaçar gênero no próprio DNA do mito de uma maneira muito diferente, muito mais óbvia e muito mais meticulosa.

Isso pode ser demonstrado pelo esquema no diagrama 1, no qual os textos foram tabulados de acordo com um padrão constituído por quatro elementos - união, tratamento ou atitude em relação aos filhos, conspiração materna e deposição. Nem todos os textos apresentam tal arranjo, claro, e alguém pode fazer a acusação, de certa forma justa, de que a concepção inteira é muito influenciada pela primazia conceitual da narrativa hesiódica. Não obstante, a tabulação nos permite observar os textos lado a lado, e também nos mostra quão particular é o tratamento encontrado na Teogonia. Uma das coisas que deveriam ficar claras de imediato é a universalidade da conspiração materna em Hesíodo - na qual a consorte/mãe conspira contra o consorte/deus por meio dos interesses de seus filhos ou por causa deles.

Agora comparemos isso com a Canção de Emergência (CTH 344) hurro-hitita, em que Kumarbi preside quase todas as funções gerativas, tanto literalmente em relação aos deuses que engendra depois de engolir os genitais de Anu, quanto nos quatro desafiadores que ele produz para depor Teshshub: Lamma, Prata, Ullikummi e Hedammu (CTH 343, 345-6, 348). Embora algumas dessas figuras sejam de fato o resultado de relações heterossexuais, a agência ou atitude da mãe no processo de sucessão é totalmente subvalorizada. ${ }^{31} \mathrm{O}$ que importa aqui são os repetidos planos de Kumarbi para depor Teshshub, e ao longo da narrativa não há lugar para a conspiradora materna tão proeminente em Hesíodo. De fato, conforme Campbell argumentou recentemente, ${ }^{32}$ os poderes geradores de Kumarbi são planejados para unificar os destinos de Anu e Kumarbi na pessoa de Teshshub e deveriam ser considerados uma inovação a partir de um padrão "mais natural" no qual uma divindade feminina estaria envolvida, já que a narrativa "transgride as leis de sexualidade e gênero

\footnotetext{
${ }^{29}$ N. T.: "aparato divino".

${ }^{30}$ Estudos de gênero e divindade na literatura próximo-oriental são um fenômeno relativamente recente: cf. Lambert (1987), Frymer-Kensky (1992), Harris (2000), Sonik (2009), Asher-Greve e Westenholz (2013), Budin (2014); cf. também acima, nota 24.

${ }^{31}$ Há referência a uma gravidez e nascimento em relação à Terra nesse processo, mas a tabuinha está bastante danificada nesse ponto, e não podemos dizer mais do que isso; cf. Beckman (2011, p. 31-2). A marginalização da divindade feminina foi notada como típica dos textos babilônicos do segundo milênio como um todo: Frymer-Kensky (1992, p. 70-80), Asher-Greve e Westenholz (2013, p. 22-8); também adiante, notas 39 e 41 .

${ }^{32}$ Campbell (2013).
} 
a fim de sublinhar o poder do deus masculino e seu papel criador". ${ }^{33}$ Apesar de todas as semelhanças com as quais começamos, a diferença entre as tradições grega e hurro-hitita quanto a esse ponto é notável.

A figura da conspiradora materna é, entretanto, evidente nos dois textos babilônios. A primeira e mais óbvia é Tiamat no Enuma Elish, e seu papel em conspirações é colocado em evidência duas vezes, primeiro $e$ contrario $^{34}$ ao se recusar a se juntar a Apsu na destruição dos filhos, resignando-se de modo efetivo "diante da morte de seu consorte pelo bem de seus filhos" (I 29-46). ${ }^{35}$ Parece ter sido assumido aqui que ela é naturalmente considerada uma figura essencial em qualquer ação desse tipo, já que Apsu se abala para tentar persuadi-la a se juntar a ele em seu plano, e a recusa dela em assentir à proposta é mais tarde voltada contra ela como uma repreensão por parte dos outros deuses (I 113-20). Conforme eles deixam claro, a recusa de Tiamat em tomar parte em uma conspiração na verdade ajuda a provocar a sucessão. A segunda ocasião é a mais óbvia (I 110-62ss.), em que Tiamat rapidamente deixa de ser uma mãe ultrajada, persuadida por seus filhos a tentar destruir o novo deus Marduk, e assim excede em sua ira contra Anšar pela deposição de Apsu, para se transformar num monstro que se configura como o típico desafiador do governo da divindade, como no Lugale (ECTSL 1.6.2) sumério ou no Épico de Anzy acadiano. ${ }^{36}$ Embora a maternidade seja uma parte importante na motivação inicial de Tiamat, sua transformação em uma fera aterrorizante no mínimo deixa de enfatizar os elementos de gênero em sua composição. ${ }^{37}$

Isso não significa negar um motivo ou função patriarcal no texto, ${ }^{38}$ ainda mais porque a criação do homem por Marduk (Tabuinha VI) certamente conta como um argumento em relação à importância relativa do papel masculino/feminino em seu universo, especialmente ao lado de cenas análogas de criação da humanidade alhures na Mesopotâmia (por exemplo, Enki e Ninmah 1-43 [ECTSL 1.1.2]; Atrahashis OB I 189ss., LB II 67ss.; Gilgamesh SB I 94104). ${ }^{39}$ No Enuma Elish, os papéis ambivalentes de Tiamat - mãe e monstro - são espelhados na dualidade, quase indeterminação, de seus objetivos face ao Mito de Sucessão: como está tentando evitar a sucessão de Marduk, ela então promove ao mesmo tempo a sucessão de seu filho, Qingu, e então consorte. Em ambas as ocasiões, entretanto, ela falha em promover o regime favorecido por ela própria até o fim almejado. Assim, aqui, temos uma conspiradora

\footnotetext{
${ }^{33}$ López-Ruiz (2010, p. 143).

${ }^{34}$ N. T.: "contrariamente".

${ }^{35}$ Harris (2000, p. 84).

${ }^{36}$ Cf. acima, n. 25.

${ }^{37}$ Harris (2000, p. 87): “O retrato bastante unilateral e misógino da antiga deusa Tiamat se relaciona a seu comportamento 'masculino', que ameaçava normas patriarcais”.

${ }^{38}$ Cf. Sonik (2009).

${ }^{39}$ Cf. Frymer-Kensky (1992, p. 70-80); Budin (2014). Selena Wisnom me lembrou de que apenas figuras masculinas (Ea, Marduk) estão envolvidas na criação da humanidade no Enuma Elish, um notável aspecto de gênero naquele poema que também coincide no modo que alhures (por exemplo, $A n \approx u)$ é a mãe que encoraja o deus a combater o desafiador, enquanto no Enuma Elish esse papel é desempenhado pelo pai de Marduk, Ea.
} 
materna do tipo geral que encontramos na tradição grega, mas uma bastante reconfigurada, em que o poeta diminui a maternidade em favor da monstruosidade e intencionalmente a faz falhar no contexto do conflito entre gerações e transferência de poder.

Também gendrificada, mas de um modo bastante diferente, é a Teogonia de Dunnu, na qual Terra sugere uma ligação sexual a seu filho Shakkan, uma união que precede o assassinato do pai por parte dele. ${ }^{40}$ Isso estabelece o padrão, a ser repetido por várias gerações, de um filho se unindo à sua mãe e/ou irmã, assassinando o pai e, às vezes, também a mãe - de fato um mito que faz Édipo se sentir um pouco amador. Intencional ou não, o primeiro incesto tem uma ramificação política na morte de $\mathrm{Ha}$ in, e suspeita-se que (apesar da natureza lacônica do texto) o assassinato de Terra, sua mãe, por parte do Mar, tinha algo a ver com algum tipo de conflito de poder emergindo do status relativo de ambos como consortes de Shakkan e a necessidade de eliminar um rival na união com Lahar. Felizmente, esse tipo de coisa se resolve nas próximas três gerações, quando tanto o pai quanto a mãe são mortos imediatamente pelo novo governante.

Assim, o gênero tem decerto um papel nas versões do Mito de Sucessão que encontramos nas tradições mesopotâmicas, embora nada como a regularidade quase formular que encontramos em Hesíodo: enquanto Gaia e Reia são bem-sucedidas em seus esforços para causar a sucessão (e Hera necessariamente falha, de maneira repetida), Tiamat no Enuma Elish causa a sucessão de modo involuntário primeiramente por meio da não participação e então por meio de uma falha; enquanto Terra em Dunnu aparentemente obtém sucesso em seu objetivo de ter o consorte substituído por seu filho, e ela é então morta por sua filha (que também acontece de ser sua rival amorosa), assim estabelecendo um padrão no qual a mãe é invariavelmente assassinada no momento da sucessão ou pouco depois. Por acaso, o retrato negativo da figura materna nesses textos é a exceção em vez da regra na literatura mesopotâmica. Por exemplo, em Enki and Ninhursag (ECTSL 1.1.1), esta última, apesar de sua ira contra Enki, ainda o auxilia em sua dificuldade ao dar à luz, enquanto em Enlil and Ninlil(ECTSL1.2.1), Ninlil persevera contra o mau tratamento que recebe de Enlil ao lhe dar filhos. A deusa-mãe é mais auxiliadora em geral nas narrativas de desafiadores de monstros, como no Épico de Anzu, no qual Mami sugere e então aconselha Ningirsu (OB) ou Ninurta (SB) em sua jornada; ou com Ninlil advertindo Ninurta depois de derrotar Asag em Lugale. ${ }^{41}$

Por si só, a comparação com o Oriente Próximo auxilia um classicista a entender melhor uma qualidade distinta na maneira como os gregos deram forma a esse tipo de narrativa para atender a suas exigências. Certamente está além da minha competência usar esse material para fazer uma generalização sobre as políticas sexuais em várias civilizações do Oriente Próximo ao longo de um enorme período de tempo, mas é surpreendente como a mesma preocupação especificamente sobre a usurpação feminina do poder masculino é encontrada apenas às vezes, em uma variedade de formas, nas tradições próximo-orientais,

\footnotetext{
${ }^{40}$ Cf. Lambert (2013, p. 387-92).

${ }^{41}$ Cf. de modo geral Frymer-Kensky (1992, p. 14-31, p. 70-80); Asher-Greve e Westenholz (2013); Gadotti (2014); também, acima, nota 39 para os modos nos quais o Enuma Elish minimiza de forma autoconsciente sua positividade materna.
} 
mas foi urdida com profundidade no próprio tecido da narrativa teológica grega. Somente a tradição grega torna a deusa uma fonte de constante perigo à manutenção da ordem divina. Sexo e gênero quase se tornaram, deveras, seus conceitos fundantes.

Essa comparação deveria ser conduzida apenas até aqui, com os traços individuais dessas várias tradições tornados mais claros por meio da analogia, mas a tentação de especular sobre a genealogia é irresistível. Como vimos, as tradições grega e mesopotâmica, ambas, refletem o potencial desestabilizador da figura feminina no Mito de Sucessão, embora a mesopotâmica desvie de seu caminho para reduzir esse potencial ou redirecioná-lo por meio de canais não gendrificados ou desgendrificados. A tradição hurro-hitita é o ponto fora da curva aqui, em relação ao modo como faz Kumarbi assumir toda a função geradora, mas em outro sentido mostra a mesma tendência dos textos mesopotâmicos de apagar ou marginalizar a conspiradora materna. Ou seja, ambas essas tradições poderiam ser vistas como reflexos ou refrações secundárias de um padrão de sucessão "original”, muito mais simples, em que uma figura (naturalmente) feminina dá à luz o deus que usurpará seu consorte - o padrão que a versão hesiódica reflete de forma mais direta e usa repetidamente. As pessoas estremecem ao fazer esse tipo de julgamento absolutista cruzando fronteiras culturais e temporais, mas tal reconstrução implicaria que as tradições próximo-orientais eram mais complexas, desenvolvidas e sofisticadas quanto a esse ponto do que a grega. Isso também sugeriria que havia modos de interação, um anatólio e outro mesopotâmico, alimentando a longa pré-história da literatura grega. É difícil acreditar que o próprio Hesíodo fosse tão multicultural ou multilíngue de modo a combinar pessoalmente essas abordagens um tanto diferentes do Mito de Sucessão pela primeira vez num contexto helênico. ${ }^{42}$

Não obstante, por mais divertido que possa ser esse tipo de especulação, esse ainda é um caso de obscura per obscuriora. ${ }^{43}$ Uma tal conclusão pode também ser muito influenciada pela primazia do modelo hesiódico em minha concepção do fenômeno, e portanto - como diz Píndaro (Olímpica 1, 52) - eu recuo. Ao menos, a evidência comparativa nos mostra quão longa, quão variada e, acima de tudo, quão sincrética era a tradição grega arcaica do mito. Conforme colocado por López-Ruiz, ${ }^{44}$ “[a]s versões sobreviventes dessas narrativas [...] dão testemunho de um rico e complexo reservatório mediterrâneo-oriental de tradições míticas no qual os gregos estiveram também mergulhando por muitos séculos".

O processo denotado por essa metáfora aquática, a propósito, não começou - e definitivamente não teve fim - com Hesíodo. Embora este artigo se concentre em sua Teogonia como nossa evidência primária para o período mais antigo, havia outras versões gregas arcaicas dessa história cósmica, e o processo de interação com o Oriente Próximo em torno dessa história continuou por muito tempo depois do texto de Hesíodo ter se tornado um clássico. Já mencionamos uma tal figura, Fílon de Biblos, mas havia outras: em seu Dificuldades e Soluções dos Primeiros Princípios (125c), o neoplatonista do século V d.C.,

\footnotetext{
${ }^{42}$ Conforme Christopher Metcalf me sugeriu, isso também combina mal com a autorrepresentação de Hesíodo como alguém com uma limitada experiência de viagem (Trabalhos e Dias 618-94).

${ }^{43}$ N. T.: ou seja, de explicar o que é obscuro por meio do que é ainda mais obscuro.

${ }^{44}$ López-Ruiz (2010, p. 127).
} 
Damáscio, cita Eudemo de Rodes (séc. IV a.C.) e um sábio fenício para o qual não há data, Mochos, em razão de uma cosmogonia que não tem traço de conflito entre gerações, mas que contém detalhes familiares como o ovo cosmogônico encontrado na tradição órfica. ${ }^{45}$ Além disso, é evidente que Berosso (séc. III a.C.), um babilônio que escreve em grego sob o regime dos Selêucidas, claramente conhecia o Enuma Elish ou algo muito parecido, ao resumir a narrativa no primeiro livro de seu Babiloníaca. ${ }^{46}$ Independentemente de como foi transmitida para o mundo grego tardio, a contínua influência da Canção de Emergência também pode ser vista na cosmogonia parcialmente preservada no Papiro Derveni do IV século, no qual Zeus aparentemente engole o falo de Urano (fr. 8, 12 Bernabé), torna-se prenhe (fr. 12, 2-4) e então procede na criação do mundo (fr. 15-18 Bernabé). ${ }^{47} \mathrm{Na}$ verdade, esses textos tardios são muito mais próximos em detalhes das tradições próximo-orientais ${ }^{48}$ e apresentam uma reivindicação muito mais convincente do que a Teogonia de Hesíodo de terem sido produzidos por interação direta e com pessoa identificável entre textos e autores específicos. No máximo, Hesíodo nos mostra que os gregos já estavam preparados há muito tempo para esses experimentos tardios, fornecendo as amplas semelhanças estruturais na narrativa que poderiam permitir uma polinização cruzada de modo ainda mais próximo e profundo. Sua Teogonia, portanto, desempenha exatamente o mesmo papel que o pano de fundo indo-europeu desempenhou para ele e sua tradição, formando a paisagem a partir da qual o território próximo-oriental parecia não apenas reconhecível, mas atraente. Essa, contudo, é uma discussão para um outro dia.

\section{Conclusão}

Para os gregos do período arcaico, a história da ascensão de Zeus ao poder e do estabelecimento de seu governo é profundamente sexualizada e gendrificada em sua natureza e lógica. Zeus não apenas possui e refreia a conspiradora materna frustrada, ele não apenas controla o comportamento sexual e o potencial de parturição das outras deusas femininas, ele não apenas evita cometer os mesmos erros sexuais de seus predecessores ao ter todos os seus filhos com uma única consorte - na verdade, a Teogonia de Hesíodo serve como um texto alvará para nada além do que a eterna dominação masculina. Essa é a distinção da perspectiva grega no tema antigo e bem disseminado do Mito de Sucessão: sua gendrificação é mais pronunciada do que na tradição hurro-hitita, que patriarcaliza ao negar papéis e agência às divindades femininas num contexto em que isso é esperado, e é ainda mais pronunciada do que na tradição mesopotâmica, cujos textos mostram explicitamente o sucesso temporário, mas a derrota definitiva, de qualquer tentativa feminina de minimizar a dominância da divindade masculina. $\mathrm{O}$ estudo comparativo nos permite observar o elemento individual

\footnotetext{
${ }^{45}$ Cf. López-Ruiz (2010, p. 130-70).

${ }^{46}$ Cf. Frahm (2010); Haubold (2013b).

${ }^{47}$ Cf. López-Ruiz (2010, p. 137-44, p. 167-9). Para uma perspectiva diferente, cf. Kotwick e Janko (2017, p. 207-12).

${ }^{48}$ Cf. Burkert (2004, p. 92).
} 
agindo dentro de seu próprio contexto; e determinar o que é distintivo em cada tradição; e assim, por fim, entendê-los todos melhor. Genealogia, ao menos da maneira como a maioria dos classicistas gostaria de realizá-la, não é nem possível nem frutífera. Mas a comparação se mantém, e seu estudo voltado para a analogia pode nos dizer muita coisa.

\section{REFERÊNCIAS}

ALLEN, N. J. Bhīṣma and Hesiod's Succession Myth. International Journal of Hindu Studies, v. 8, p. $57-79,2004$.

ARCHI, A. Orality, direct speech and the Kumarbi Cycle. Altorientalische Forschungen, v. 36, p. 209-29, 2009.

ASHER-GREVE, J. Stepping into the Maelstrom. Women, gender and Ancient Near Eastern scholarship. NIN - Journal of Gender Studies in Antiquity, v. 1, p. 1-22, 2001.

ASHER-GREVE, J.; WESTENHOLZ, J. Goddesses in context. On divine powers, roles, relationships and gender in Mesopotamian textual and visual sources. Göttingen: Vandenhoeck \& Ruprecht, 2013.

BACHVAROVA, M. From Hittite to Homer. Cambridge: Cambridge University Press, 2016.

BACHVAROVA, M. Hurro-Hittite stories and Hittite pregnancy and birth rituals. In: CHAVALAS, M. W. (Ed.). Women in the Ancient Near East. London: Routledge, 2014, p. 272306.

BECKMAN, G. Primordial obstetrics. “The Song of Emergence” (CTH 344). In: HUTTER, M.; HUTTER-BRAUNSAR (Ed.). Hethitische Literatur: Überlieferungsprozesse, Textstrukturen, Ausdrucksformen und Nachwirken; Akten des Symposiums vom 18. bis 20. Februar 2010 in Bonn. Münster: Ugarit-Verlag, 2011, p. 25-34.

BOLGER, D. (Ed.). Gender through time in the Ancient Near East. Lanham MD: AltaMira Press, 2008.

BONNAFÉ, A. Eros et Eris: Mariages divins et mythe de succession chez Hesiode. Lyon: Presses Universitaires de Lyon, 1985.

BRIQUEL, D. La “Théogonie” d'Hésiode. Essai de comparaison indo-européenne. Revue de l'histoire des religions, v. 197, p. 243-76,1980.

BUDIN, S. Fertility and gender in the Ancient Near East. In: MASTERSON, M.; SORKIN RABINOWITZ, N.; ROBSON, J. (Ed.). Sex in Antiquity. Exploring gender and sexuality in the Ancient World. London: Routledge, 2014, p. 30-49.

BURKERT, W. Babylon, Memphis, Persepolis. Eastern contexts of Greek. Culture. Cambridge, MA: Harvard University Press, 2004. 
CAMPBELL, D. On the Theogonies of Hesiod and the Hurrians. In: SCURLOCK, J.; BEAL, R. H. (Ed.). Creation and chaos. A reconsideration of Hermann Gunkel's Chaoskampf Hypothesis. Winona Lake: Eisenbrauns, 2013, p. 26-43.

COOPER, J. S. Female trouble and troubled males. Roiled seas, decadent royals, and Mesopotamian masculinities in myth and practice. In: ZSOLNAY, I. (Ed.). Being a man... Negotiating ancient constructs of masculinity. London: Routledge, 2017, p. 112-24.

CORS I MEYA, J. Traces of the ancient origin of some mythic components in Philon of Byblos' Phoenician History. In: MOLINA, M.; MÁRQUEZ ROWE, I.; SANMARTÍN, J. (Ed.). Arbor scientia: estudios del Próximo Oriente Antiguo dedicados a Gregorio del Olmo Lete con ocasión de su 65 aniversario. Barcelona: Editorial AUSA, 1999-2000, p. 341-8.

CORTI, C. The so-called 'Theogony' or 'Kingship in Heaven'. The name of the song. Studi Micenei ed Egeo-Anatolici, v. 49, p. 109-21, 2007.

FRAHM, E. Counter-texts, commentaries, and adaptations. Politically motivated responses to the Babylonian Epic of Creation in Mesopotamia, the Biblical World, and elsewhere. Orient, v. 45 , p. 3-33, 2010.

FRYMER-KENSKY, T. S. In the wake of goddesses. Women, culture, and the Biblical transformation of pagan myths. New York: Ballantine Books, 1992.

GADOTTI, A. Presence in absentia. Portraits of the feminine in Sumerian literature. Journal of the American Oriental Society, v. 131, p. 195-206, 2011.

GADOTTI, A. The feminine in myth and epic. In: CHAVALAS, M. W. (Ed.). Women in the Ancient Near East. London: Routledge, 2014, p. 28-58.

HARRIS, R. Gender and aging in Mesopotamia. Oklahoma: University of Oklahoma Press, 2000.

HAUBOLD, J. Greece and Mesopotamia. Dialogues in literature. Cambridge: Cambridge University Press, 2013.

HAUBOLD, J. 'The wisdom of the Chaldaeans'. Reading Berossos, Babyloniaca Book 1. In: HAUBOLD, J. et al. (Ed.). The world of Berossos. Wiesbaden: Harrassowitz Verlag, 2013b, p. 31-46.

HOFFNER, H.; BECKMAN, G. Hittite myths. 2nd ed. Atlanta: Society of Biblical Literature, 1998.

KATZ, J. A. The Prehistory and analogues of Hesiod's poetry. In: LONEY, A. C.; SCULLY, S. (Ed.). The Oxford handbook of Hesiod. Oxford: Oxford University Press, 2018, p. 62-78.

KELLY, A. Gendering the Succession Myth in Hesiod and the Ancient Near East. In: KELLY; METCALF (Ed.). Gods and Mortals in early Greek and Near Eastern Mythology. Cambridge: Cambridge University Press, 2020. No prelo. 
KELLY, A. Homeric battle narrative and the Ancient Near East. In: CAIRNS, D.; SCODEL, R. (Ed.). Defining Greek narrative. Edinburgh: Edinburgh University Press, 2014, p. 29-54.

KELLY, A. How to end an orally-derived epic poem. Transactions of the American Philological Association, v. 137, p. 371-402, 2007.

KELLY, A. The Babylonian captivity of Homer: the case of the Dios Apate. Rheinisches Museum, v. 151, p. 259-304, 2008.

KELLY, A.; METCALF, C. (Ed.). Divine narratives in Early Greece and the Ancient Near East. Cambridge: Cambridge University Press, 2020. No prelo.

KELLY, A. D.; METCALF, C. (Ed.). Gods and Mortals in early Greek and Near Eastern Mythology. Cambridge: Cambridge University Press, 2020. No prelo.

KOTWICK, M.; JANKO, R. Der Papyrus von Derveni. Berlin: De Gruyter, 2017.

LAMBERT, W. G. Babylonian creation myths. Winona Lake: Eisenbrauns, 2013.

LAMBERT, W. G. Goddesses in the Pantheon. A reflection of women in society. In: DURAND, J.-M. (Ed.). La femme dans le Proche-Orient antique. Paris: Éditions recherche sur les civilisations, 1987 , p. 125-30.

LION, B.; MICHEL, C. (Ed.). The role of women in work and society in the ancient Near East. Leiden: De Gruyter, 2016.

LITTLETON, C. Scott. Is the 'Kingship in Heaven' theme Indo-European? In: CARDONA, G.; HOENIGSWALD, H. M.; SENN, A. (Ed.). Indo-European and the Indo-Europeans. Papers presented at the Third Indo-European Conference at the University of Pennsylvania. Philadelphia: University of Pennsylvania Press, 1970a, p. 383-404.

LITTLETON, C. Scott. The 'Kingship in Heaven’ Theme. In: PUHVEL, J. (Ed.). Myth and law among the Indo-Europeans. Berkeley: University of California Press, 1970b, p. 83-121.

LÓPEZ-RUIZ, C. When the gods were born. Greek cosmogonies and the Near East, Cambridge, MA: Harvard University Press, 2010.

LÓPEZ-RUIZ, C. Gods, heroes, and monsters. A sourcebook of Greek, Roman, and Near Eastern myths in translation. Oxford: Oxford University Press, 2014a.

LÓPEZ-RUIZ, C. Greek and Near Eastern mythologies. A story of Mediterranean encounters. In: EDMUNDS, L. (Ed.). Approaches to Greek myth. 2nd ed. Baltimore: Johns Hopkins University Press, 2014b, p. 152-99.

LYE, J. Gendering Hesiod. In: LONEY, A. C.; SCULLY, S. (Ed.). The Oxford handbook of Hesiod. Oxford: Oxford University Press, 2018, p. 175-90.

METCALF, C. The gods rich in praise. Oxford: Oxford University Press, 2015. 
MONDI, R. Comparative approaches to Greek and Near Eastern mythology. In: EDMUNDS, L. (Ed.). Approaches to Greek myth. Baltimore: Johns Hopkins University Press, 1990, p. 141-98.

PARPOLA, S.; WHITING, R. M. (Ed.). Sex and gender in the Ancient Near East. Proceedings of the 47th Rencontre Assyriologique Internationale, Helsinki, July 2-6, 2001. Helsinki: Neo-Assyrian Text Corpus Project, 2002.

PELED, I. Masculinities and third gender. The origins and nature of an institutionalized genderotherness in the Ancient Near East. Münster: Ugarit-Verlag, 2016.

PUHVEL, J. Comparative mythology. Baltimore: Johns Hopkins University Press, 1987.

ROLLINGER, R. Fighting heroes and fighting gods: the Iliad and Ancient Near Eastern contexts. In: KELLY; METCALF (Ed.). Gods and Mortals in early Greek and Near Eastern Mythology. Cambridge: Cambridge University Press, 2020. No prelo.

ROLLINGER, R. Old battles, new horizons: the Ancient Near East and the Homeric epics. In: ROLLINGER, R.; VAN DONGEN, E. (Ed.). Mesopotamia in the Ancient World. Impact, continuities, parallels. Münster: Ugarit-Verlag, 2015, p. 5-32.

ROLLINGER, R.; SCHNEGG, K. (Ed.). Kulturkontakte in antiken Welten. Vom Denkmodell zum Fallbeispiel. Proceedings des internationalen Kolloquiums aus Anlass des 60. Geburtstages von Christoph Ulf, Innsbruck, 26. bis 30. Januar 2009. Leuven, Paris, Walpole MA: Peeters Publishers, 2014.

RUTHERFORD, I. Borrowing, non-borrowing, and blocking. A new approach to East-West literary interactions. In: In: KELLY; METCALF (Ed.). Gods and Mortals in early Greek and Near Eastern Mythology. Cambridge: Cambridge University Press, 2020. No prelo.

RUTHERFORD, I. Hesiod and the literary traditions of the Near East. In: MONTANARI, F.; RENGAKOS, A.; TSAGALIS, C. (Ed.). Brill's companion to Hesiod. Leiden: Brill, 2009, p. $9-36$.

RUTHERFORD, I. Kingship in Heaven in Anatolia, Syria and Greece. Patterns of convergence and divergence. In: DIGNAS, B.; AUDLEY-MILLER, L. (Ed.). Wandering myths. Transcultural uses of myth in the Ancient World. Berlin: De Gruyter, 2018, p. 6-22.

SCURLOCK, J.; BEAL, R. H. (Ed.). Creation and chaos. A reconsideration of Hermann Gunkel's Chaoskampf Hypothesis. Winona Lake: Eisenbraubs, 2013.

SERGENT, B. Genèse de l'Inde. Paris: Payot, 1997.

SONIK, K. Gender matters in the Enuma Elish. In: BEAL, R. H.; HOLLOWAY, S. W.; SCURLOCK, J. (Ed.). In the wake of Tikva Frymer-Kensky. Piscataway: Gorgias Press, 2009, p. 85-101.

STOL, M. Women in the Ancient Near East. Translated by H. Richardson \& M. Richardson. Leiden: De Gruyter, 2016. 
STRAUSS CLAY, J.; GILAN, A. The Hittite "Song of Emergence" and the Theogony. Philologus, v. 58, p. 1-9, 2014.

VAN DONGEN, E. The concept of 'the Near East'. A reconsideration. In: ROLLINGER; SCHNEGG (Ed.). Kulturkontakte in antiken Welten. Vom Denkmodell zum Fallbeispiel. Proceedings des internationalen Kolloquiums aus Anlass des 60. Geburtstages von Christoph Ulf, Innsbruck, 26. bis 30. Januar 2009. Leuven, Paris, Walpole MA: Peeters Publishers, 2014, p. 253-67.

VAN DONGEN, E. The 'Kingship in Heaven' theme of the Hesiodic Theogony. Origin, function, composition. Greek, Roman, and Byzantine Studies, v. 51, p. 180-201, 2011.

WATKINS, C. How to kill a dragon. Aspects of Indo-European poetics. Oxford: Oxford University Press, 1995.

WEST, M. L. Indo-European poetry and myth. Oxford: Oxford University Press, 2007.

WEST, M. L. The east face of Helicon. West Asiatic elements in Greek poetry and myth. Oxford: Oxford University Press, 1997.

WIKANDER, S. Histoire des Ouranides. Cabiers du Sud, v. 36, p. 9-17, 1952.

WITZEL, E. The origins of the world's mythologies. Oxford: Oxford University Press, 2011. 